The following is a continuation of the ephemeris published by Dr. Ebell in No. 4517 of the Astronomische Nachrichten, and on the accompanying chart the apparent path of the comet among the stars is approximately shown; the new elements, upon which these positions depend, give October 27 as the time of perihelion passage :-

Ephemeris (12h. M.T. Berlin).

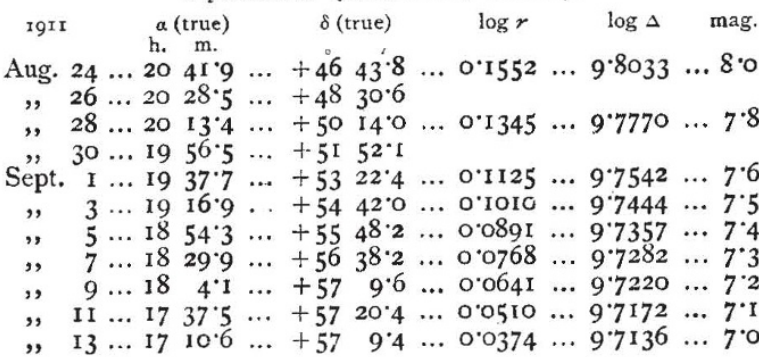

It will be noted that on August 26 the comet will pass very near to $\omega$ Cygni (magnitude 4.9 ), and on September ro within a few minutes of $\xi$ Draconis (magnitude 3.9 ).

The New Canals on Mars.-It will be remembered by readers of these columns that, during the last opposition of Mars, Prof. Lowell claimed to have discovered conspicuous canals which reference to the large accumulation of earlier observations showed to be new; they were not to be found on any of the earlier drawings.

Telegraphing to the Kiel Centralstelle, Prof. Lowell now states that these two new features near Syrtis are still visible. The importance of establishing the novelty and permanence of such conspicuous "canali" as these appear to be cannot be overrated.

A Quickly Moving Comet-like Object.-Dr. Franz reports the observation at Breslau on July 22 of a rapidly moving nebulous object, which may have been a comet very near to the earth. At $13 \mathrm{~h} .4 \mathrm{~m}$. (M.E.T.), the position of this object was $\alpha=4$ h. 15.om., $\delta=+20^{\circ} 36^{\prime}$ (1855.0), and during an interval of six minutes the R.A. altered by about $3 \mathrm{~m}$., while the declination remained the same. This nebulous-looking body was of about the sixth magnitude and about $6^{\prime}$ in diameter, not unlike the Kiess comet which had been observed just before.

The observers at Kiel searched unsuccessfully on July 23 for an object answering to the conditions named by $\mathrm{Dr}$. Franz, and Dr. Graff was equally unsuccessful at Bergedorf on July 24 ; both he and Dr. Franz were clouded out on July 23 (Astronomische Nachrichten, No. 45I7).

ObServations of Nova Lacertæ.-A number of magnitude and position observations of Nova Lacertæ appear in No. 4509 of the Astronomische Nachrichten. Prof. Eginitis shows that the colour of the star changed from red to bluish-white during the period January to March, its magnitude meanwhile decreasing from 7.9 to 8.9 . M. Luizet shows that this change of colour was very rapid during the first six weeks, and then the colour became nearly constant. Herr Jost's observations of magnitude show very small oscillations up to the end of February, and then a nearly constant diminution until the beginning of May.

At the Simeis Observatory Prof. Beljawsky made an elaborate investigation of the nova's magnitude as shown on various photographs taken through different coloured screens. The results, together with the measures of position, are given and discussed in No. 4I (vol. iv., No. 5) of the Mitteilungen der Nikolai-Hauptsternwarte $z u$ Pulkowo.

Prominences OBSERVED ON APRIL 28.-In view of the total eclipse of the sun on April 28 last, Prof. Ricco made special arrangements for the visual and photographic observations of prominences at Rome and Catania, and now publishes the results in No. 4, vol. xl., of the Memorie di Astrofisica ed Astronomia. There was a large prominence in position-angle $48^{\circ}$ (N. through E.), and lesser ones at $36^{\circ}-42^{\circ}$. $163^{\circ}-168^{\circ}$ (given as $192^{\circ}-108^{\circ}$ on the figure accompanying the article), and $294^{\circ}-300^{\circ}$.

NO. 2 I82, VOL. 87 ]
A Star with Considerable Proper Motion.-Mr. Baldwin reports, in No. 4513 of the Astronomische Nachrichten, that the observations made at Melbourne Observatory show the star C.P.D. $-70^{\circ} 447$ to have a large proper motion amounting to -0.07 IIs. in R.A. and + I.2 I4" in declination. The position of the star, for 1900.0 , is 5h. $45 \mathrm{~m} .4 \mathrm{r} \cdot 036 \mathrm{~s} .,-70^{\circ} \mathrm{I2}^{\prime} 50.9 \mathrm{I}^{\prime \prime}$, and it was observed at Melbourne in 1892 and 1907 .

\section{AN ASTRONOMICAL SURVEY OF SOME PEMBROKESHIRE CIRCLES.}

THE Rev. W. Done Bushell first directed the attention of the members of the Cambrian Archæological Association five years ago to some monuments in Pembrokeshire as illustrative of Sir Norman Lockyer's findings elsewhere, and a well-illustrated paper of fifty-two pages, published in the journal of that association, shows that, so far as Wales is concerned, the archrologists wish to give this " new thing " a hearing.

The author confines himself to ten groups of monuments on the southern slopes of the Prescelly Hills, covering a tract of land seven miles from east to west. As during the last five years he has made repeated visits to the district, he has gathered almost heartrending evidence of the progressive destruction of ancient monuments. "There were at Eithbed until very recently three circles, and probably three cromlechs also were associated with them. They are now no more. The largest was destroyed, we know not when or how" (pp. I7, 18). "We find this circle duly given in the earlier edition of the 25-inch Ordnance Map; it is entirely absent from the later edition issued in 1908." The author was able to trace its outline.; "It has an average diameter of no less than I50 feet." "Two other circles ... have both of them been wilfully destroyed," one in 1905 and the other in 1909. "These circles, with the accompanying cromlechs, must have formed a very noble and important group before they were thus demolished." The author, fortunately, had photographed some of the monuments before they were destroyed. Last year he recognised some of the temple materials in an "ugly house which stands close by, a veritable monument of shame" (pp. 19, 20). All archæologists will, of course, deplore such vandalism; but the significance of the loss is well expressed in the author's remark :- "We may add that the existence of three circles in immediate contiguity suggests, as in the case of the Hurlers and elsewhere, adjustments rendered necessary by precession" (p. 22).

At Cil-y-maen-1lwyd, in the same district, an observer about the year 1738 saw " a circle of mighty stones very much like Stonehenge in Wiltshire, or rather like the Rollrych Stones in Oxfordshire" (p. 38). There remains just one of the mighty eighty stones.

Of the existing remnants of temples second to few in Britain, the author has secured most useful angular measures. He acknowledges the assistance of his son, $\mathrm{Mr}$. Warin F. Bushell, and of Lieut.-Colonel Tupman, in preparing the plans given. A useful declination table for lat. $\mathbf{5 2}^{\circ}$ by the latter is given as an appendix. The paper is an admirable illustration of what may be done with little trouble in every district towards recording the testimony of the stones, the speediest and most effective method of outwitting the vandals. Photographs are good, plans are better, but measures are indispensable.

Given trustworthy data, we can put up with any deductions. Some of the author's opinions are tolerable only on such ground. Because of the difficulty in these latitudes of observing any celestial bodies right on the horizon, he is inclined to think that the alignments had only a ceremonial use. Early man, he thinks, "did not require the aid of an astronomer" (p. 44). "Nor would so many observation-circles have been required had their prime object been, as has been suggested (Lockyer, 'Stonehenge,' p. 17), the determination of the seasons. England has many churches, but only one Greenwich "' (pp. 45, 46). Yet in a passage cited the author speaks of "adjustments rendered necessary by precession." Such, however, are some opinions which the author puts forth as " alternatives to any premature acceptance of Sir Norman Lockyer's 
interesting theory, at least in its entirety" (p. 44). Nothing like a proved. alternative is offered, nor is it shown that the data supplied require any alternatives. Such a happy observation as that cromlechs generally are oriented so as to command the most extensive view obtainable is not universally true to the facts, and could not have been always " a primary consideration with the cromlechbuilders" (p. 20). The exceptions prove what the primary consideration was, as at St. Lythans' fine cromlech, which is definitely oriented to the equinox in the opposite direction to the extensive view. JohN GRIFFITH.

\section{RECENT ENGLISH AGRICULTURAL PUBLICATIONS.}

$\mathrm{SCIENTIFIC}$ work in agriculture in this country is published exclusively in the Journal of Agricultural Science, but there are certain papers published in the technical journals which possess considerable scientific interest. These alone will be dealt with in the present article.

The Board of Agriculture publishes each month the Journal of the Board of Agriculture, which can only be described as an unqualified success. There are usually three or four signed articles, primarily of technical importance, but often of scientific value as well, followed by a number of short articles or notes summarising work done on a particular subject, or directing attention to important work being done elsewhere.

The progress of the sugar beet industry in Norfolk is described by Mr. W. E. Sawyer. Last year's trials showed beyond doubt that sugar beet could be produced in sufficient quantity, and of the necessary good quality, for the purposes of a factory. This year it is sought to ascertain whether the crop will pay as well as other crops, and in organising the work advantage is being taken of last year's experience. Generally speaking, it has been demonstrated that sugar beet can be produced in most parts of England, but we now require experiments on the large commercial scale to ascertain whether or not the industry will be profitable.

Dr. Goodwin writes on molasses and sugar foods for live stock. Molasses, whether from beet or from cane sugar factories, contains about 30 to 35 per cent. of sucrose and 25 to 30 per cent. of dextrose and other sugars. There are also present some nitrogenous compounds, betaine, aminoacids, \&c., and also some ash constituents, but the great value of molasses as a food consists in its sugars. Unfortunately there are certain drawbacks to its use : it is very sticky and difficult to handle, and is said to be liable to theft. To overcome these difficulties the practice has arisen of adding some absorbent material to the molasses and making a mixture that could be dried, powdered, and handled easily. The absorbents are of the most varied kinds; cocoanut meal, hay, spent hops, bran, sugar-cane pith, and peat have all been used, and not a few extravagant claims have been put forward by the patentees about the beneficial effects of the absorbent. Dr. Goodwin examines certain of these claims, and shows by actual digestibility trials with sheep that only a small proportion of the added cellulose is digested in some cases.

The relation of weeds to crops is discussed by Miss Brenchley. Over a limited area, where the climatic conditions showed no great variation, i.e., between Harpenden and Bedford, there was a clear connection traceable between the weeds and the nature of the soil, but none between the weeds and crop, with a few readily explained exceptions. The so-called "seeds" crops, clover, and rye grass, \&c., effectually keep down certain weeds, no doubt because they so densely cover the ground; other weeds will only grow in the thin patches of cereal crops, and in other open situations.

It has long been an agricultural practice to grow certain crops simply with the intention of ploughing them into the ground, and thus adding organic matter to the soil to be converted into humus. Mr. Hall describes experiments made at Rothamsted on the relative effects of mustard, rape, crimson clover, and vetches: as was expected, the leguminosæ gave the largest increase in subsequent crops. At Woburn a different result was obtained, it being found that mustard gave better results than the leguminous tares.

1 The Journal of the Board of Agricult ire; The Journal of the Royal Agricultural Society.

NO. 2182, VOL. 87$]$
Dr. Lander, in an interesting note, shows that small amounts of prussic acid, such as might be generated from a linseed cake in which the glucoside-splitting enzyme had not been destroyed, are not necessarily harmful to stock. In view of the widespread occurrence of cyanogenetic enzymes, it is highly desirable that authoritative information should be at hand as to the effect of continuous small doses of hydrocyanic acid on animals.

The Journal of the Royal Agricultural Society is published once a year only, and its appearance is always an event in the agricultural world. In the current number there is a paper by Dr. Russell, giving a connected account of the work he and his colleagues have been doing on the production of plant food in the soil, and bringing together a number of agricultural practices, previously unexplained, that fall into line with the recent work with which he is associated.

Mr. W. W. Skeat contributes an interesting account of the origin of some old agricultural words, directing special attention to the "Dictionary of English Plant-names," by Britten and Holland, and the "English Dialect Dictionary." Sir John McFadyean deals with the very important question of tuberculosis in cattle. The idea still finds credence that the offspring of tuberculous cattle will necessarily develop tuberculosis : experiments, on the other hand, have shown that if the calves are at once removed from their dams and kept free from infection they do not become tuberculous. Nor does Sir John admit that they show any special tendency to tuberculosis. All breeds of cattle are liable to tuberculosis, but no families exhibit any special liability not shown generally by their particular breed.

State aid to agriculture in Canada is authoritatively described by Mr. E. H. Godfrey, of the Canadian Agricultural Department. Mr. Godfrey has the enormous advantage of knowing English institutions, and his article will, therefore, be found of great interest to all engaged in agricultural administrative work in this country. In addition, there are the usual reports from the consulting botanist, chemist, and zoologist; Prof. Biffen reports a case where the somewhat rare hoary cress (Lepidium draba) obtained a footing on arable land, and spread to such an extent as to become a nuisance; while Dr. Voelcker reports the effect of zinc and other salts on crop growth in pots.

\section{MEDICAL RESEARCH IN INDIA.}

THE scientific memoirs by officers of the Medical and Sanitary Departments of the Government of India, ${ }^{1}$ issued from time to time, contain matter and researches of the utmost importance and value.

Memoir 43 deals with the relation of tetanus to the hypodermic or intramuscular injection of quinine. For some forms of malaria injection of quinine is by far the most efficient treatment, but every now and then is followed by the dreaded tetanus or lockjaw, even when every possible care has been taken to ensure the sterility of the fluid and of the syringe used to inject it.

Tetanus is caused by a bacillus which occasionally is present in dust and earth, and may be introduced into a wound, and so give rise to "traumatic tetanus." It is a curious fact that tetanus spores free from other organisms and free from any adherent toxin may be injected into an animal without harm, and may remain latent at the site of inoculation for months. If, however, the spores have adherent toxin upon them, or if at the same time a little weak lactic acid is injected, the organism grows and multiplies and sets up tetanus. Apparently some agent must be present which weakens the resistance of the tissues before the tetanus bacillus can develop. Sir D. Semple, the author of this memoir, finds that quinine injected into the tissues produces necrosis or death of the tissue at the site of injection, and that pure washed tetanus spores

1 No. 43: "The Relation of Tetantus to the Hypodermic or Intramuscular Injection of Quinine." By Lieut.-Col. Sir D. Semple, Kt. Pp. v+6r. Price $1 s .2 d$.

No. 44: "The Preparation of a Safe and Efficient Antirabic Vaccine." By Lieut.-Col. Sir D. Semple, Kt. Pp. $\mathrm{v}+, 32$. Price $9 d$.

No. 45: "Epidemic Dropsy in Calcutta." Being the First Report of an Inquiry carried out by Major G. D. W. Greig. Pp. ii $+47+$ map + vi charts. Price 2s. (Calcutta: Government Printing Office, rgrr.) 